\title{
Hepatocellular Carcinoma in a Case of Adult-onset Type II Citrullinemia
}

\author{
Naoki Hagiwara, Yoshiki SekiJIMa, Yo-ichi TaKeI, Shu-ichi IKedA, \\ Seiji KAWASAKI*, Keiko KOBAYASHI** and Takeyori SAHEKI**
}

\begin{abstract}
A 40-year-old woman was admitted with altered consciousness and hyperammonemia after she had delivered her first baby. DNA analysis of the citrin gene and enzymatic assay of argininosuccinate synthetase in the liver led to a diagnosis of adult-onset type II citrullinemia (CTLN2). She was also found to have hepatocellular carcinoma (HCC) and underwent palliative surgery consisting of partial liver section of the HCC. Delivery may be a trigger for the development of CTLN2, while certain pathologic conditions associated with citrin gene abnormality are likely to induce hepatocellular carcinoma in patients with this disorder.

(Internal Medicine 42: 978-982, 2003)
\end{abstract}

Key words: citrulline, citrin, delivery, hepatocellular carcinoma, fatty change

\section{Introduction}

Citrullinemia is a rare autosomal recessive disease caused by a deficiency of argininosuccinate synthetase (ASS), one of the five urea cycle enzymes mainly located in the liver (1). This disorder can be classified into three types based on enzyme abnormality.

The neonatal/infantile form (CTLN1) is known to be caused by mutations of the ASS gene, whereas there are no apparent abnormalities in hepatic ASS mRNA or within the ASS gene locus of patients with adult-onset type II citrullinemia (CTLN2) (2). Recently, citrin (SLC25A13 gene), which appears to be a calcium-dependent mitochondrial solute transporter with a role in the urea cycle function, has been identified as a causative gene of CTLN2 (3).
Patients with CTLN2 show various neurological manifestations closely resembling those of hepatic encephalopathy, and chronic pancreatitis, hypertriglyceridemia and hepatocellular carcinoma (HCC) are known to be complications of this disease $(4,5)$. In addition, it has been noted that individuals with the mutated citrin gene suffer transient intrahepatic cholestasis in the neonatal period or early infancy $(6,7)$.

Here, we report a case with CTLN2 who developed the disease soon after delivery and was found to have HCC without liver cirrhosis.

\section{Case Report}

The patient was a 40-year-old Japanese woman without any specific family history, past medical treatment or alcohol abuse. She had been very fond of nuts since childhood.

In October 2000, after the normal delivery of her first son in a nearby hospital, she developed disturbance of consciousness accompanied by abnormal behavior. In December she became somnolent and was admitted to another hospital. Laboratory findings revealed a highly increased concentration of plasma ammonia $(187 \mu \mathrm{g} / \mathrm{ml}$; normal <66) and citrulline $(373.4 \mathrm{nmol} / \mathrm{ml}$; normal 17-43). She was diagnosed as having hepatic encephalopathy due to hypercitrullinemia. Her consciousness subsequently cleared and she was transferred to our hospital on December 22, 2000.

At the initial examination, she was $156 \mathrm{~cm}$ tall and weighed $38.5 \mathrm{~kg}$. Her mood was slightly unstable and a mild flapping tremor was evoked, but other physical and neurological findings were normal. Laboratory findings showed increased levels of plasma ammonia $(71 \mu \mathrm{g} / \mathrm{ml}$; normal $<66)$, citrulline $(377.0 \mathrm{nmol} / \mathrm{ml}$; normal 17-43), and arginine (258.2 nmol/ml; normal 54-130). Serum concentrations of pancreatic secretory trypsin inhibitor (PSTI) $(32 \mathrm{ng} / \mathrm{ml}$; normal 4.6-12.2), $\alpha$-fetoprotein (AFP) $(460.5 \mathrm{ng} / \mathrm{ml}$; normal

From the Third Department of Medicine, *the First Department of Surgery, Shinshu University School of Medicine, Matsumoto and **the Department of Biochemistry, Faculty of Medicine, Kagoshima University, Kagoshima

Received for publication February 17, 2003; Accepted for publication June 13, 2003

Reprint requests should be addressed to Dr. Yo-ichi Takei, the Third Department of Medicine, Shinshu University School of Medicine, 3-1-1 Asahi, Matsumoto 390-8621 



Figure 1. Radiological findings of $\mathrm{HCC}$ and histological findings of biopsied liver tissue. A: Abdominal computed tomography (CT) of a tumor with a diameter of $3 \mathrm{~cm}$ in segment 6 , which appears to have a low-density area. B: Tumor staining from feeding artery is obvious in hepatic artery angiography. C: Gross finding of the tumor removed by palliative partial liver resection (tumor size: $2.2 \mathrm{~cm} \times 3.2 \mathrm{~cm}$ ). Since the tumor had been treated with trans-arterial embolization, the histopathological finding is necrosis only. D: Biopsied tissue of the non-carcinomatous lesion: presence of severely fatty liver without any cirrhotic changes (HE stain, $\times 38)$.

$<20)$ and protein induced by vitamin $\mathrm{K}$ absence-II (PIVKAII) $(466 \mathrm{mAU} / \mathrm{ml}$; normal <40) were also elevated. However, routine liver function test results, including those for transaminases, were normal, and neither $\mathrm{HBs}$ antigen nor HCV antibody was positive. Abdominal computed tomography (CT) revealed a solid mass lesion in segment 6 (S6) of the liver (Fig. 1A). It also showed early enhancement of contrast medium in the arterial phase and subsequent washout in the portal phase, and the mass was clearly visualized by hepatic artery angiography (Fig. 1B).

Gene analysis of citrin was performed and the existence of a homozygote for IVS11+1G $>$ A mutation was proven. The patient was diagnosed with CTLN2 and HCC. To enable her to qualify for cadaveric liver transplantation, the HCC had to be removed first. Trans-arterial embolization (TAE) of the HCC was performed on January 27, 2001, followed by palliative surgery consisting of partial liver resection, including the tumor lesion, on August 8, 2001. Liver biopsy was carried out simultaneously and a selective reduction in ASS activity was demonstrated $(0.0033 \mathrm{U} / \mathrm{mg} /$ protein; normal $0.033 \pm 0.012)$. Histological examination showed marked fatty metamorphosis, but no infiltration of inflammatory cells or structural changes including fibrosis were evident (Fig. 1D).

After the operation, serum levels of AFP and PIVKA-II became normalized, but the plasma ammonia concentration fluctuated between 200 and $300 \mu \mathrm{g} / \mathrm{ml}$. In addition, hepatic encephalopathy with the state higher than grade II 

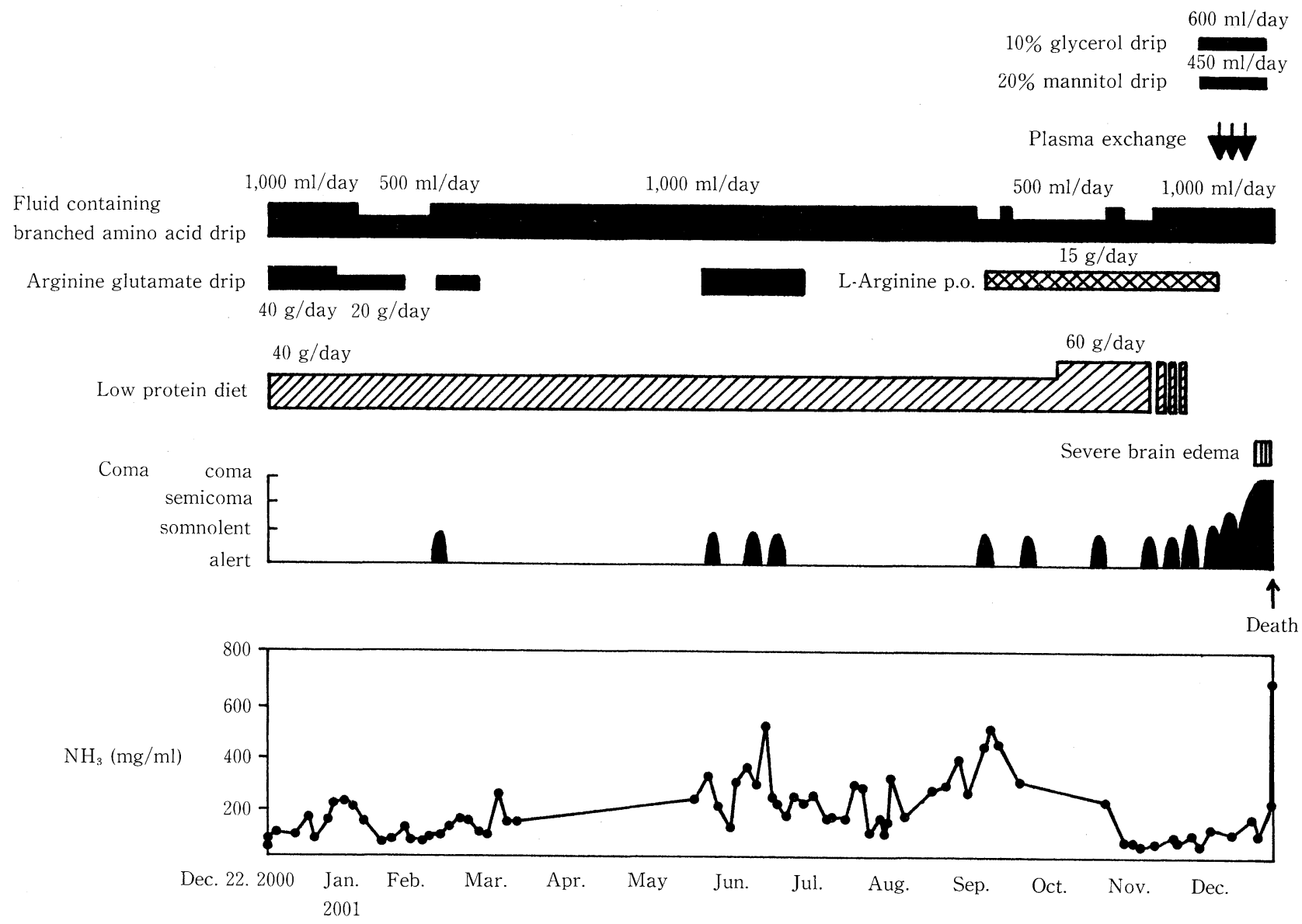

Figure 2. Clinical course of the patient.

occasionally recurred (at least once in a month), even though she was on a strict regimen of conservative treatment (Fig. 2 ). This regimen consisted of intravenous infusion of hyperalimentation fluid with branched chain amino acids (BCAA), accompanied by a low protein diet (40 g/day) and oral administration of lactulose $(58.5 \mathrm{mg} /$ day $)$ and kanamycin $(1,500 \mathrm{mg} /$ day $)$. The long-term use of medication producing glucose loading and protein-restricted nutrition exacerbated her fatty liver, and liver dysfunctions; prolongation of prothrombin time (30.9 s; normal 10-12), a reduced percentage on the hepaplastin test (15.1\%; normal 70-130) and reduced percentage of factor VII $(7.8 \%$; normal 54.0-162) became apparent. L-arginine ( $15 \mathrm{~g} /$ day) was therefore added orally and protein intake was increased to $60 \mathrm{~g}$ per day to compensate for the deteriorated liver function. After this treatment the concentration of plasma ammonia appeared to be reduced (Fig. 2). However, the patient fell into a deep coma on December 20, 2001 and triple plasma exchange did not have any therapeutic effect. She died on December 27, 2001.

\section{Discussion}

CTLN2 is characterized by a liver-specific deficiency of ASS protein with normal kinetic properties, showing very high levels of plasma ammonia and citrulline (2). Several mutations in the causative citrin gene have been identified among patients with a clinical picture of CTLN2 $(3,8)$. The diagnosis for our case was confirmed by the analysis of both DNA and hepatic ASS activity.

The age of onset of CTLN2 ranges from 11 to 72 (9), with a sudden onset of disturbed consciousness, expressed as, for example, disorientation, restlessness and drowsiness, being common initial symptoms (4). Once symptoms appear, most patients develop rapidly progressing encephalopathy and finally die of severe brain edema within a few years of onset (Table 1). In the present patient, the long-term use of medication producing glucose loading and protein-restricted nutrition exacerbated the fatty liver and liver dysfunction. Her liver function had reached its limits. As a result, she suffered repeated occurrences of loss of consciousness and eventually died of cerebral edema associated with hepatic failure.

Although the exact mechanism that leads to the development of CTLN2 has not yet been identified, several reports 
Type II Citrullinemia with HCC

Table 1. Summary of Citrullinemia (Modified from Ref. 13)

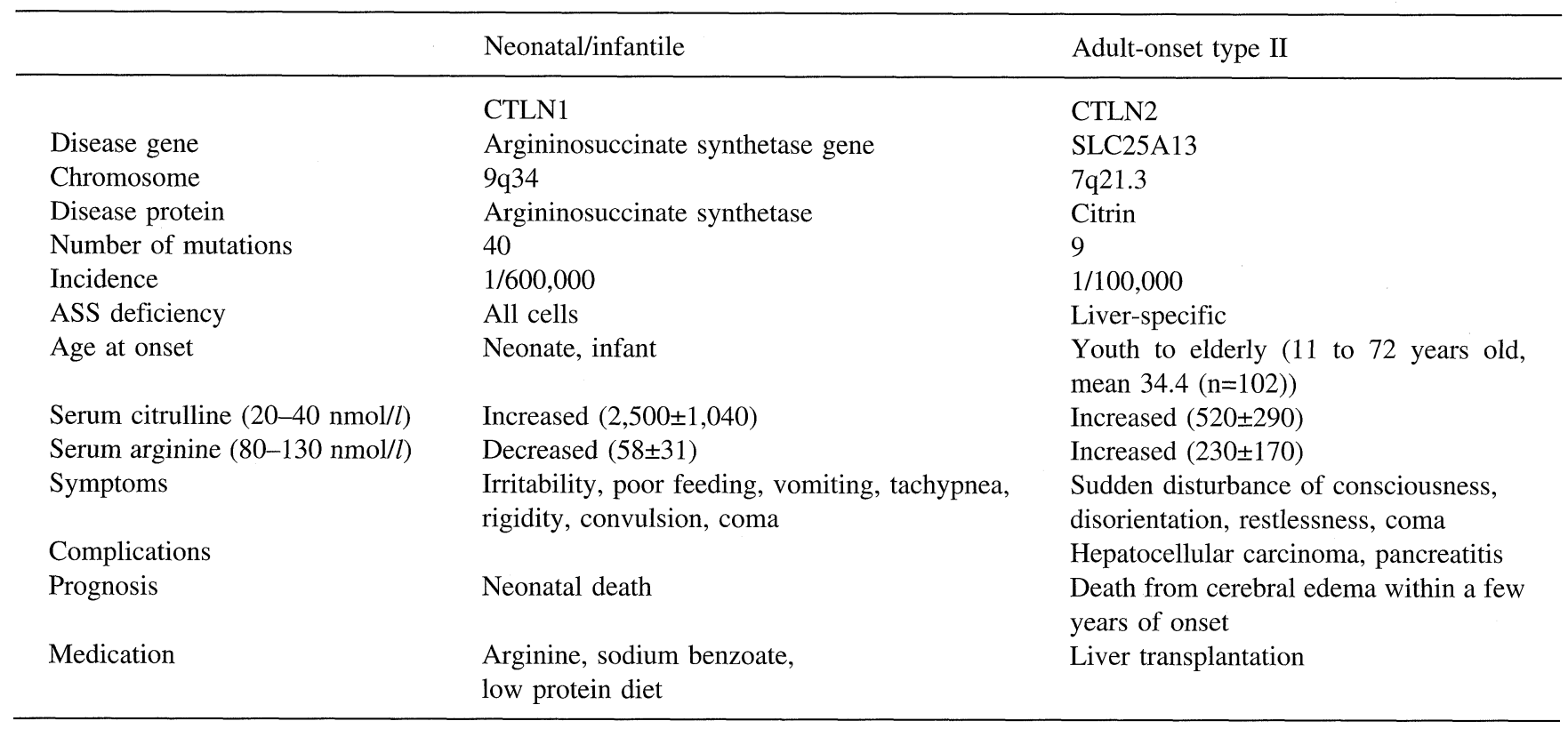

have suggested that certain forms of stress, including infection, hormonal factors, and drugs, might be a trigger for this disease (10-12). There has been no previous report, however, of a patient whose CTLN2 started soon after delivery. Pregnancy and/or delivery are potentially stressful and are accompanied by rapid changes in the hormonal environment. It is therefore quite reasonable to assume that the pregnancy and/or the delivery may have induced the symptoms of CTLN2 in this case.

The present patient was unique in that she had an $\mathrm{HCC}$ when she developed the clinical picture of CTLN2. A high incidence (about 8 to 14\%) of $\mathrm{HCC}$ has been reported for CTLN2 patients (13), and all those with HCC had two other characteristics: they were relatively young when they developed HCC and lacked any underlying cirrhotic disorder (14). Both of these features were also observed in our patient, while she had no history of hepatitis-related viral infection or exposure to substances known to induce HCC such as thorium dioxide (Thorotrast). Excessive citrulline promotes the uptake of $\left[6-{ }^{3} \mathrm{H}\right]$ thymidine (TdR) in hepatocytes and it is thought that this increased uptake can be ascribed to hepatocyte proliferation caused by the enhancement of DNA synthesis, which may lead to hepatocarcinogenesis (14).

Fatty liver is usually seen in CTLN2 (4). Nonalcoholic steatohepatitis (NASH) is also characterized by fatty change of the liver, and progress to cirrhosis and HCC (15). Free fatty acids then accumulate in the liver through altered fat homeostasis, and oxidative stress and lipid peroxidation may play a role in liver damage seen in NASH. In the case of CTLN2, the oxidative stress or lipid peroxidation in the fatty liver may be one of the causes of HCC.

In classical type citrullinemia (CTLN1), the histopathological findings consist mainly of mitochondrial abnormalities with fatty changes in liver tissue like CTLN2 (16).
However, there are few reports of CTLN1 complicated with HCC. A recent study of neonatal intrahepatic cholestasis has shown that individuals with a mutated citrin gene start to suffer from metabolic abnormalities in hepatocytes from birth (5): in addition to cholestasis, hypoproteinemia, galactosemia and hypoglycemia have also been observed in small numbers of these neonates (17). It has therefore been suggested that in patients with CTLN2 the long-term presence of all these pathologic conditions including hypercitrullinemia and oxidative stress induce $\mathrm{HCC}$ without preceding hepatitis or cirrhosis.

Finally, with reference to the treatment of CTLN2, the present patient did not qualify for cadaveric liver transplantation because her $\mathrm{HCC}$ exceeded $3 \mathrm{~cm}$. TAE for $\mathrm{HCC}$ and tumor resection were therefore performed first, after which she was placed on the waiting list for a liver transplant from a cadaveric donor. All conservative medical treatments have been shown to be unsatisfactory (9) and liver transplantation is now considered the only effective treatment for patients with this disorder $(4,18,19)$. More than 20 patients underwent this operation, including living-related partial transplantation, and most of them could return to their previous social lives (4). To save patients with CTLN2, it is essential that liver transplantation be performed before irreversible brain damage can occur.

\section{References}

1) Brishilow SW, Horwich AL. Urea cycle enzymes. in: The Metabolic and Molecular Basis of Inherited Disease, Scriver CR, Beaudet AL, Sly WS, Valle D, Eds. 7th ed. McGraw-Hill Information Service Co., New York, 1995: 1187.

2) Saheki T, Kobayashi K, Inoue I. Hereditary disorders of the urea cycle in man: biochemical and molecular approaches. Rev Physiol Biochem Pharmacol 108: 21-68, 1987. 


\section{HAGIWARA et al}

3) Kobayashi K, Sinasac DS, Iijima M, et al. The gene mutated in adultonset type II citrullinemia encodes a putative mitochondrial carrier protein. Nat Genet 22: 159-163, 1999.

4) Ikeda S, Yazaki M, Takei Y, et al. Type II (adult onset) citrullinemia: clinical pictures and the therapeutic effect of liver transplantation. $\mathrm{J}$ Neurol Neurosurg Psychiatry 71: 663-670, 2001.

5) Saheki T, Kobayashi K. Mitochondrial aspartate glutamate carrier (citrin) deficiency as the cause of adult-onset type II citrullinemia (CTLN2) and idiopathic neonatal hepatitis (NICCD). Human Genet 47: 333-341, 2002.

6) Tazawa Y, Kobayashi K, Ohura T, et al. Infantiie cholestatic jaundice associated with adult-onset type II citrullinemia. J Pediatr 138: 735740, 2001.

7) Tomomasa T, Kobayashi K, Kaneko H, et al. Possible clinical and histologic manifestations of adult-onset type II citrullinemia in early infancy. J Pediatr 138: 741-743, 2001.

8) Yasuda T, Yamaguchi N, Kobayashi K, et al. Identification of two novel mutations in the SLC25A13 gene and detection of seven mutations in 102 patients with adult-onset type II citrullinemia. Hum Genet 107: 537-545, 2000.

9) Takenaka K, Yasuda I, Araki H, et al. Type II citrullinemia in an elderly patient treated with living related partial liver transplantation. Intern Med 39: 553-558, 2000.

10) Ogawa $K$, Takashima $S$, Hirade $S$, Nimura A, Ueno H, Inoue H. Adultonset type II citrullinemia in a patient undergoing continuous ambulatory peritoneal dialysis. Rinsho Shinkeigaku (Clin Neurol) 38: 826830, 1998 (in Japanese with English Abstract).

11) Ishii $A$, Ohkoshi $N$, Oka $Y$, Ban $S$, Takahashi $A$. A case of citrullinemia associated with ACTH deficiency, rapidly developing coma. Rinsho Shinkeigaku (Clin Neurol) 32: 853-858, 1992 (in Japanese with English Abstract).

12) Shiohama N, Sugita $Y$, Imamura N, Sato T, Mizuno Y. Type II citrullinemia triggered by acetaminophen. No To Shinkei (Brain Nerve) 45: 865-870, 1993 (in Japanese with English Abstract).

13) Kobayashi K, Iijima M, Yasuda T, et al. Type II citrullinemia (citrin deficiency): A mysterious disease caused by a defect of calciumbinding mitochondrial carrier protein. in: Calcium: The Molecular Basis of Calcium Action in Biology and Medicine. Pochet R, Donato R, Haiech J, Heizmann C, Gerke V Eds. Kluwer Academic Publishers, Deventer, The Netherlands, 2000: 565-587.

14) Nakamura $M$, Okamoto $Y$, Morita $T$, et al. Promoting effect of citrulline in hepatocarcinogenesis: Possible mechanism in hypercitrullinemia. Hepatology 11: 819-823, 1990.

15) Harrison SA, Kadakia S, Lang KA, Schenker S. Nonalcoholic steatohepatitis: what we know in the new millennium. Am J Gastroenterol 97: 2714-2724, 2002.

16) Zamora SA, Pinto A, Scott RB, Parsons HG. Mitochondrial abnormalities of liver in two children with citrullinaemia. J Inherit Metab Dis 20: 509-516, 1997.

17) Naito E, Ito M, Matsuura $S$, et al. Type II citrullinemia (citrin deficiency) in a neonate with hypergalactosemia detected by mass screening. J Inherit Metab Dis 25: 71-76, 2002.

18) Kasahara M, Ohwada $S$, Takeichi $T$, et al. Living-related liver transplantation for type II citrullinemia using a graft from heterozygote donor. Transplantation 71: 157-159, 2001.

19) Yazaki M, Ikeda S, Takei Y, et al. Complete neurological recovery of an adult patient with type II citrullinemia after living related partial liver transplantation. Transplantation 62: 1679-1684, 1996. 